\title{
Study of Interleukin 23 Gene Polymorphism in Egyptian Patients with Allergic Rhinitis
}

\author{
Kassem M. Kassem ${ }^{\mathrm{a}}$, Mohsen M. Abdelrazik ${ }^{\mathrm{a}}$, Hamada F. Hashem ${ }^{\mathrm{a}}$, Heba M. Abdelkarim ${ }^{\mathrm{b}}$, Mona H. \\ Mahmoud ${ }^{\mathrm{c}}$
}

a

Department of

otorhinolaryngology, Benha faculty of medicine, Benha university, Egypt. ${ }^{\mathrm{b}}$ Department of biochemistry, Benha faculty of medicine, Benha University, Egypt. c Department of otorhinolaryngology, Benha health insurance hospital, Egypt.

Correspondence to: Mona $\mathrm{H}$.

Mahmoud, Department of otorhinolaryngology, Benha health insurance hospital, Egypt.

email:

monahussein87.mh@gmail.com

Received: 1 March 2020

Accepted: 8 March 2020

\begin{abstract}
:
Objective: Polymorphism of the interleukin-23 receptor gene corresponds with susceptibility to several immune-related diseases. For the terminal differentiation of IL-17-producing effector T-helper cells in vivo, the interleukin-23 receptor gene is of vital importance. As shown recently, Th17 cells probably have a great influence on the pathogenesis of allergic airway diseases. Our intention was to establish an association between polymorphisms in the IL-23R gene and allergic rhinitis (AR) in Egyptians. Methods: we included $100 \mathrm{AR}$ patients and 75 control Egyptian subjects in a case-control study. The study involved obtaining blood samples for DNA extraction, genotyping and determination of a selected single-nucleotide polymorphisms in IL-23R by performing TaqMan assay PCR. Results: A substantially growing prevalence of the homozygous rs7517847 GG genotype and $\mathrm{G}$ allele appeared in the AR patients unlike that observed in

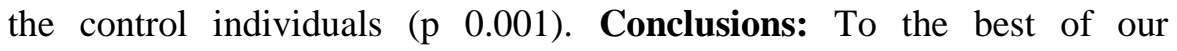
knowledge, this is the first study to demonstrate an important association between polymorphisms in IL-23R and AR in the Egyptian population. A strong association between rs7517847 in a SNP of IL-23R, and AR was
\end{abstract} identified.

\section{Introduction:}

Allergic Rhinitis is an allergic reaction producing an inflammation of nasal mucosa on inhaling an allergen such as dust, dander or pollen. About $20 \%$ of populations suffer from allergic diseases which include allergic rhinitis, atopic dermatitis, bronchial asthma and food allergy. Allergic inflammation is the result of complex immunological cascade leading to dysregulated production of $\mathrm{T}$ helper 2 (Th2) cell derived cytokines 
such as interleukin (IL-4), IL-5 and IL-13 which in return triggers $\operatorname{IgE}$,eosinophil and mucus production (1).

Several studies have investigated singlenucleotide polymorphisms (SNPs) in genes encoding the molecules implicated in the pathogenesis of allergic rhinitis; including specific ILs and their receptors. The interleukin-23 (IL.23) is a heterodimeric cytokine composed of two disulfide-bridged subunits, p19 which is unique to IL23 and p40 which is shared with IL-12. This complex is expressed by activated dendritic cells and has biological activities that are similar but not equal to those of IL-12(2).

As observed in recent studies, several SNPs in the IL-23R gene are found to be associated with immune-related diseases, including Crohn's disease, rheumatoid arthritis, Behcet's disease, and ankylosing spondylitis (3). However, the linkage between $I L-23 R$ SNPs and susceptibility to rhinitis allergy has not been wellestablished. In the present study, we aimed to investigate whether the polymorphisms of the $I L-23 R$ gene contribute to the development of rhinitis allergy in Egyptian population.

\section{Method:}

This is s a case/control study. One hundred and seventy five, Egyptian individual were collected from outpatient clinic of Benha university hospital and Benha health insurance hospital between January 2017 and December 2017.

One hundred patients with allergic rhinitis with age range from 9 to 55 years old patient, nasal/endoscopic inspection, and the presence of positive allergen as per skin prick tests (SPT: Allergopharma, Hamburg, Germany), and responses to a panel of common allergens, were used to diagnose allergic rhinitis.

A total of 18 inhaled allergens were tested, including house dust, grass, tree, mold, food, and weed panel allergens. The typical symptoms defined by ARIA (4) include 2 or more AR symptoms (nasal congestion, rhinorrhoea, nasal itching, and sneezing) lasting for 4 or more days in a week in the year before the study was begun. A positive SPT result was defined as that where a wheal is larger than or equal to one half of the diameter of the histamine control, and at least $3 \mathrm{~mm}$ larger than the diameter of that shown by the negative control.

Skin prick tests were performed by specialists, technicians, and nurses, while AR was diagnosed by the clinical rhinologists. Also, 75 apparently healthy 
individuals of matched age and sex, were included as a control group.

\section{Ethical Considerations:}

This study was approved by the ethics committee on research involving human subjects of Benha Faculty of Medicine. Informed consent was obtained from each individual before sample collection.

\section{SNP Selection:}

We selected (IL23R) (rs7517847) as the studied SNP, as many studies previously demonstrated a strong association between (IL23R) (rs7517847) with certain immunerelated diseases(Di, et al 2013)

\section{Sampling}

Three ml venous blood was collected from each subject by clean venipuncture using disposable plastic syringe and placed on ethylene diamine-tetra-acetic salt (EDTAK3) $(1.2 \mathrm{mg} / \mathrm{mL})$ as an anticoagulant and stored at $-80^{\circ} \mathrm{C}$ for molecular assay of IL23R genotypes

Table 1: Clinical features and demographic characteristics of the study population.

Characteristic AR (n=100), Control $(n=75)$

Gender [Male/Female] 51/49 38/37

Age [Mean (range)] 26.27(9-55) 25.69(11-50)

All the blood samples were collected in ethylene diamine-tetra- acetate tubes and stored at -80C until use. Using the QIAamp DNA Blood Mini Kit, genomic DNA was extracted and the target region was amplified by performing PCR. PCR restriction was applied to genotype this SNP.

1- The probes were designed with minor groove binder (MGB) and non-fluorescent quencher (NFQ) at the $3^{\prime}$ end, whereas the $5^{\prime}$ end contained the fluorescence reporter dyes 2'-chloro 7'-phenyl-1,4-dichloro-6 $\begin{array}{llll}\text { carboxyfluorescein } & \text { (VIC) } & \text { or } 6\end{array}$ carboxyfluorescein (FAM). The wild type probe labeled with VIC dye while the variant probe labeled with FAM dye. All solutions were thawed on ice, gently vortexed and briefly centrifuged. In thin walled $0.1 \mu \mathrm{l}$ PCR tube for each sample, the following was added for a total $20 \mu \mathrm{l}$ reaction volume.

2-PCR was performed in thermal cycler according to the following conditions: Real-time PCR was performed in a volume of $20_{\mathrm{u}} 1$ using Rotorgene real time PCR system (Qiagen- S.Korea). The reaction was set with $1 X$ TaqMan Universal Master Mix, 1X Taqman assay and the reaction volume was completed by nuclease free water. Thermal cycling conditions were as following: $60 \mathrm{C}$ for $30 \mathrm{sec}, 95 \mathrm{C}$ for $10 \mathrm{~min}$, 
40 cycles of denaturation $95^{\circ} \mathrm{C}$ for $15 \mathrm{sec}$ and annealing/extension $60^{\circ} \mathrm{C}$ for $1 \mathrm{~min}$.

\begin{tabular}{|l|l|}
\hline $\begin{array}{c}\text { TAQMAN } \\
\text { UNIVERSAL } \\
\text { MMIX II }\end{array}$ & $10 \mu \mathrm{l}$ \\
\hline $\begin{array}{c}\text { TAQMAN SNP } \\
\text { ASSAYS }\end{array}$ & $1 \mu \mathrm{l}$ \\
\hline Template DNA & $7 \mu \mathrm{l}$ \\
\hline Nuclease-free Water & $2 \mu \mathrm{l}$ \\
\hline Total & $20 \mu \mathrm{l}$ \\
\hline
\end{tabular}

\section{Data analysis:}

The data were analysed on Rotorgene real time PCR thermal cycler system and the related software for analysis and interpretation through allelic discrimination.

\section{Statistical analysis:}

Data were coded and entered using the statistical package SPSS version 25. Data was summarized using mean and standard deviation for quantitative variables and frequencies (number of cases) and relative frequencies (percentages) for categorical variables.

Comparisons between quantitative variables were done using unpaired $\mathrm{T}$ test (Chan, 2003a). For comparing categorical data, Chi square $(\chi 2)$ test was performed. Exact test was used instead when the expected frequency is less than 5 (Chan, 2003b). Genotype and allele frequencies were compared between the disease and the control groups using logistic regression. Odds ratio (OR) with $95 \%$ confidence intervals was calculated $\mathrm{p}$ values less than 0.05 were considered as statistically significant.

\section{Results:}

The two groups (case and control) were comparable with respect to mean age, gender, and workplace ratio. Pearson ChiSquare analysis of the ratios of male: female and indoor: outdoor work between the control and the study groups was performed (P.0.05).

The mean age values for the control individuals and the AR cohorts were 25.96y (ranging from $11-45 \mathrm{y}$ ), and $26.27 \mathrm{y}$ (ranging from 9-55 y), respectively, which were not significantly different (P.0.05; measured by t-test)

The results of genotypic and allelic frequency analysis are shown in Table 3. With respect to the frequencies of rs7517847, AR patients and exhibited a significant exhibited a significant difference. The frequencies of the rs7517847 GG genotype and the minor allele $G$ in the $A R$ patients were very high, unlike that observed in the case of the control individuals ( $p$ $0.001,91.5 \%$ and $8.5 \%$ respectively). 
Table (2):age of cases and control groups

\begin{tabular}{|c|c|c|c|c|c|}
\hline \multicolumn{6}{|c|}{ Group Statistics } \\
\hline \multirow{2}{*}{\multicolumn{2}{|c|}{ Group }} & & & Std. & Std. Error \\
\hline & & $\mathbf{N}$ & Mean & Deviation & Mean \\
\hline \multirow[t]{2}{*}{ Age } & Cases & 100 & 26.2700 & 10.90256 & 1.09026 \\
\hline & Control & 75 & 25.9600 & 9.86728 & 1.13938 \\
\hline
\end{tabular}

Table (3): genotypic and allelic frequency analysis

\begin{tabular}{|c|c|c|c|c|c|}
\hline & & & \multicolumn{2}{|c|}{ Group } & \multirow[t]{2}{*}{ Total } \\
\hline & & & control & cases & \\
\hline \multirow[t]{12}{*}{ Genotype } & TT (Wild type) & Count & $59_{\mathrm{a}}$ & $10_{\mathrm{b}}$ & 69 \\
\hline & & $\%$ within genotype & $85.5 \%$ & $14.5 \%$ & $100.0 \%$ \\
\hline & & $\%$ within group & $78.7 \%$ & $10.0 \%$ & $39.4 \%$ \\
\hline & & $\%$ of Total & $33.7 \%$ & $5.7 \%$ & $39.4 \%$ \\
\hline & GG (Mutant) & Count & $7 \mathrm{a}$ & $75_{\mathrm{b}}$ & 82 \\
\hline & & $\%$ within genotype & $8.5 \%$ & $91.5 \%$ & $100.0 \%$ \\
\hline & & $\%$ within group & $9.3 \%$ & $75.0 \%$ & $46.9 \%$ \\
\hline & & $\%$ of Total & $4.0 \%$ & $42.9 \%$ & $46.9 \%$ \\
\hline & GT (Heterozygous) & Count & $9 \mathrm{a}$ & $15_{\mathrm{a}}$ & 24 \\
\hline & & $\%$ within genotype & $37.5 \%$ & $62.5 \%$ & $100.0 \%$ \\
\hline & & $\%$ within group & $12.0 \%$ & $15.0 \%$ & $13.7 \%$ \\
\hline & & $\%$ of Total & $5.1 \%$ & $8.6 \%$ & $13.7 \%$ \\
\hline \multirow[t]{4}{*}{ Total } & & Count & 75 & 100 & 175 \\
\hline & & $\%$ within genotype & $42.9 \%$ & $57.1 \%$ & $100.0 \%$ \\
\hline & & $\%$ within group & $100.0 \%$ & $100.0 \%$ & $100.0 \%$ \\
\hline & & $\%$ of Total & $42.9 \%$ & $57.1 \%$ & $100.0 \%$ \\
\hline
\end{tabular}

Each subscript letter denotes a subset of group categories whose column proportions do not differ significantly from each other at the 0.05 level. 


\section{Discussion:}

This study determined an association between IL-23R polymorphisms and AR susceptibility in Egyptian population and confirmed a SNP, rs7517847, in IL-23R that has a relationship with AR. In order to a find a relation with immune diseases, we have investigated the most common IL-23R SNP related to immune diseases rs7517847. First, we selected AR patients strictly according to the criteria of ARIA (Allergic Rhinitis and Its Impact on Asthma) and excluded the ones who did not fit the criteria.

Second, we chose unrelated healthy individuals from the same geographic region as that of the AR patients'; all the study participants were similar with respect to their age, sex and occupation.

Finally, to verify the results of genotyping by PCR-, we repeated the sequencing of $20 \%$ of the samples, for which we obtained the exact same results as those obtained for the first genotyping. These approaches were taken to ensure the accuracy of the results of this study. As stated in our study, the frequency of presence of the GG genotype and $\mathrm{G}$ allele of rs7517847 in AR patients 91.5\% presented a significant increase while the frequency of the GG genotype in the control group was $8.5 \%$, which suggest an important susceptibility factor to this disease. Also in this study the frequency of presence of the TT genotype and T allele of rs7517847 in AR patients were $14.5 \%$ while in the control group they were $85.5 \%$.) similar results was found in a previous study which found an association between IL-23R polymorphism and AR susceptibility in Chinese patients and confirmed a novel SNP, rs7517847, in IL-23R that has a relationship with AR. they have investigated many SNPs.

The most common IL-23R SNP related to immune diseases are rs7517847, rs11209032, and rs1343151, although rs17375018 was not shown to be associated with other diseases, by analyzing their results, it is clear that the GG haplotype formed by the rs17375018 and rs7517847 SNPs is a susceptible haplotype, whereas the AT haplotype formed by these 2 SNPs is a protective haplotype. These results suggest that the rs17375018 and rs7517847 SNPs may play a role in both the processes.(3) According to this results we can consider rs7517847 strongly related to allergic rhinitis one of the immune diseases that agree with previous studies that found a relation between this SNP and other immune 
diseases as Crohn's, gout, and ankylosing spondilytis. ${ }^{(5,6)}$ These results conform to those of the studies on Crohn's disease (CD) and ulcerative colitis, in which rs7517847G/T allele had the strongest association with $\mathrm{CD}$ risk $^{(\mathbf{5})}$.

Also both genotypic and allelic frequencies of rs7517847 differed significantly between gout patients and controls $\left(\chi^{2}=6.792\right.$, df $=$ $2, P=0.034$ by genotype; $\chi^{2}=4.202$, df $=$ $1, P=0.04$ by allele). ${ }^{(6)}$

In conclusion further studies are required to determine whether rs17375018, rs1343151and haplotype AGTG influence AR. Validation and understanding of this IL-23R relationship and the influence of IL23R variants on the IL-17A/IL-23 pathway will be important to increase the understanding about the pathogenesis of AR.

\section{References:}

1. Chan YH (2003a): Biostatistics102: Quantitative Data - Parametric \& Non-parametric Tests. Singapore Med J.; 44(8): 391-396.

2. Chan YH (2003b): Biostatistics 103: Qualitative Data -Tests of Independence. Singapore Med J.;44(10): 498-503

To cite this article: Kassem M. Kassem, Mohsen M. Abdelrazik, Hamada F. Hashem, Heba Mohamed Abdelkarim, Mona H. Mahmoud Study of Interleukin 23 Gene Polymorphism in Egyptian Patients with Allergic Rhinitis. BMF, 2020; 37(2): 432- 438. DOI:10.21608/bmfj.2020.17970.1090
3. Ciprandi G,Filaci G, Battaglia F andFenoglio D(2010): Peripheral Th-17 cells inallergic rhinitis:Newevidence.

International

Immunopharmacology (10) 2: 226-229

4. Lupardus, P. J., \& Garcia, K. C. (2008). The structure ofinterleukin-23 reveals the molecular basis of p40 subunit sharing with interleukin12. Journal of molecular biology, 382(4), 931941.

5. Di $\mathrm{Hu}$, Guohua $\mathrm{Hu}$, Jing Zhu, Yang Shen, Houyong Kang and Suling Hong (2013): Association between Polymorphisms of the IL23R Gene and Allergic Rhinitis in a Chinese Han Population. PLoS One. ; 8(5): 63-85.

6. Bousquet J, Khaltaev N, Cruz AA, Denburg J, Fokkens WJ, et al. (2008) Allergic Rhinitis and its Impact on Asthma (ARIA) 2008 update (in collaboration with the World Health Organization,GA(2)LEN and AllerGen). Allergy 63 Suppl 86: 8-160.

7. Dermot P.B. McGovern, MD, PhD, Jerome I. Rotter, MD, [...], and Kent D.(2009) Genetic epistasis of IL23/IL17 pathway genes in Crohn's disease Inflamm Bowel Dis. June ; 15(6): 883-889. doi:10.1002/ibd.20855

8. Shiguo Liu ,Hongme $\mathrm{He}$,RenchaoYu, LinHan,CanWang, Ying Cui (2015): The rs7517847 polymorphism in the IL23R gene is associated with gout in a Chinese Han male population Modern Rheumatology Volume 25, 2015 - Issue 3 Pages 449-452 